\title{
Let the Pictures Speak about Themselves: Contribution of W.J.T. Mitchell on Philosophy of Image
}

\section{Anastasia Jessica Adinda Susanti ${ }^{1}$}

Abstract: This research examines the contribution of W.J.T. Mitchell, especially on the philosophy of image. Image has been so long treated as an object. W.J.T. Mitchell located image as a subject that produced self-reflection, even capable to create a theory about themself. The contributions of Mitchell on philosophy of image are manifested on his concepts: pictorial turn, the distinction of image and picture, mixed media, meta-picture, and bio-picture.

Keywords: W.J.T. Mitchell, Picture, Image, Philosophy

\footnotetext{
${ }^{1}$ Doctoral School of Philosophy, University of Szeged, 13 Dugonics square, Szeged, H-6720, Hungary, anastasiajessica89@gmail.com
} 


\section{Introduction}

Philosophical discourse on image has taken place since ancient Greece to the contemporary era. It ranges from Plato on image or copy of the real world; Augustine on the memory-image; Wittgenstein on picture theory of language; Roland Barthes on image, text, music; Michel Foucault on the seeable and the sayable; to Jacques Ranciere on the future of image.

However, in those theories, image is so often treated as an object. W.J.T. Mitchell located image as a subject that produced self-reflection, even capable to create a theory about themself. Mitchell's Picture Theory is not a theory of picture but a picture theory, a theory by the picture itself.

This research aims to examine contribution of W.J.T. Mitchell, especially on the philosophy of image. This article is divided into four main parts: introduction, brief biography of Mitchell, Mitchell's inspiration, picture theory: picture as a living thing, conclusion.

\section{Brief Biography of Mitchell}

W.J.T. (William John Thomas) Mitchell (1942) is well-known for his works, "Iconology: Image, Text, Ideology" (1986) and "Picture Theory" (1994). He is also known for his notion on the power of image in the social and political context. Mitchell graduated from Johns Hopkins University, for Doctoral Degree, in 1968. He has been teaching since 1977 at the University of Chicago. Currently, he is Professor both in the English and the Art History departments, University of Chicago. He is also an editor on journal Critical Inquiry. His work ranges from media theory, visual art, visual culture, iconology, to literature. ${ }^{2}$

\section{Mitchell's Inspiration}

W.J.T. Mitchell has been inspired by Wittgenstein especially in his statement: "A picture held us captive". Wittgenstein's Picture theory states there is an identical logical structure of language and the structure of reality. (Glock, 2008: 36). For Wittgenstein, we can portray facts in a picture. Picture presents a state of affairs of the world. In other words, pictures become a model of reality". (Wittgenstein, 2002: 9).

Derrida's Deconstruction also gives a contribution to Mitchell's attention to the visible and material traces of writing. Derrida de-centers the "phonocentrism" model of language by shifting attention to the writing. Phonologism is Derrida's term for the privilege given to a model of language based on speech, because of a presumption that speech is presence in the language. It means the repression of writing or writing as a difference. (Derrida, 2002:426). Derrida changes his concern on writing not only as simple transcribes or "stony echo of muted words" but as "lithography before words", a metaphonetic. (Derrida, 2002: 259).

Mitchell is also inspired by Michel Foucault, especially about power and knowledge. Foucault exposes the rupture between the discursive and the "visible," the seeable and the sayable, in "scopic regimes" of modernity. (Mitchell, 1992:12). Mitchell, following Foucault, defines power, not as something that one "has" but a relationship one enjoys or suffers. Follows Foucault, Mitchell says "if we want to understand the power of pictures, we need to look at their internal relations of domination and resistance, as well as their external relations with spectators and with the world". (Mitchell, 1994: 324).

${ }^{2}$ https://english.uchicago.edu/faculty/w-j-t-mitchell 


\section{Picture Theory: Picture as a Living Thing}

\subsection{Pictorial Turn}

According to Mitchell, the philosophical discourse has shifted from linguistic turn to pictorial turn. Linguistic Turn asserts that thoughts can be comprehensively expressed in language. (Glock, 2008:35). In the pictorial turn, it is not language but image that determines all meanings of terms in both in cultural theory and everyday public discourse. (Mitchell, 1992:13).

The pictorial turn is not naïve mimesis, copy, or correspondence theories of representation. The pictorial turn is seen rather as a post-linguistic, post-semiotic rediscovery of the picture or as a complex interplay between visuality, apparatus, institutions, discourse, bodies, and figurality. (Mitchell, 1994:16).

Mitchell argues that the status of a picture in pictorial turn is, in Thomas Kuhn's concept, between "paradigm" and an "anomaly" because the picture was seen as an unsolved problem. (Mitchell, 1994:13). According to Mitchell, further explanation about pictures is still needed, such as; what are the pictures, what is the relation between picture and language, and how they related to the world. (Mitchell, 1994:13).

In a position between 'paradigm' and 'anomaly', pictures in pictorial turn are often seen as peculiar friction and discomfort thing across disciplines and intellectual inquiry areas. (Mitchell, 1994:13). For example, in the second half of the twentieth century, we encountered a paradox about the picture. On the one hand, the abundance of pictures is inescapable in the era of video and cybernetic technology and the age of electronic reproduction. On the other hand, the fear of the image has arisen at the same time. There is anxiety on the "power of images" that will destroy previous culture (which is based on literature), their creators, and also their manipulators. (Mitchell, 1994:15).

\subsection{The distinction of image and picture}

W.J.T. Mitchell distinguishes between image and picture. The picture is material support or physical medium of images (paint, stone, metal). An image is an event or happening rather than an object, which always appears in material support. (Mitchell, 2015: 30.). The picture can be destroyed easier than an image. For instance, The Golden Calf sculpture as a picture can be easily destroyed. However, the image of the Golden Calf then reappears as an object in a verbal narrative and also in painting. The picture or physical support can be destroyed but the image remains to survive, as a memory in the mind. (Mitchell, 2015: 32).

In his essay "Image Science", Mitchell mentioned that "fundamental law of the physics of image is: images cannot be destroyed". Similar to a "law of conservation" that governs matter and energy in the physical world, as Mitchell argued, images can neither created nor destroyed. Indeed, somebody can create images in their drawings. However, images are always images of something, and they are always images that logically and temporally precede the 'new' images. The 'new images' are only the new combinations of the previous images. We can not recognize an image if an image were completely new. (Mitchell, 2015: 32-33).

\subsection{Mixed Media}

According to Mitchell, none of the media can practice alone. In his essay "There are no Visual Media", he proofs that an argument of "there are a pure media like "visual" or "textual" only" 
is only fallacious thinking. Mitchell examined across various disciplines, the form of arts, and school of thoughts, from painting, photography, theater to architecture, from ancient Greeks to postmodernism. Discourse about media too often begins with the assumption that various media (text, image, photography, literature) are isolated. For Mitchell, any instance of media is a case of blending or hybridity media. The boundaries between texts and images are drawn only by a history of practical differences in the use of different sorts of symbolic marks, but not by some metaphysical entities. (Verstegen, 2017: 142-143).

Although all media is mixed media, it does not mean that the notion of mixed media has no importance. The argument of "all media is mixed-media" does not mean the impossibility of distinguishing one medium from another. (Mitchell, 2005:260) Mitchell takes an association with the specificity of media which is a recipe in cooking. To make cooking, many ingredients combined in a specific way, proportion, temperature, and amount of time. All media, like cooking, are mixed media. One can affirm 'all media is mixed media', without losing the concept of medium specificity. (Mitchell, 2005:261-262).

On the relation of image and text, Mitchell states that "textuality is already inside the image" and "the visual representation(s)... are already immanent in the words". (Mitchell, 1994: 9899). The textuality becomes "literally" visible in two ways, which are, in the medium of writing, and the utterance of gesture language, the visible language of the Deaf. (Mitchell, 1994: 99). On the other hand, the visual representation is also immanent in "the fabric of description, narrative "vision", represented objects and places, metaphor, and formal arrangements". (Mitchell, 1994: 99).

Mitchell divided three kinds of typography for 'image and text', as follows: 1) image/text as a gap between text and image; 2) imagetext as a composite of image and text, such as on graphic novel, comics, and photo-text; and 3) image-text as the relations of the visual and verbal that inherent one to each other (Mitchell, 1994:89). The image-text, for example, appears on the mixed composition of vision and language in images or memory. (Mitchell, 2015: 39).

\subsection{Metapicture}

The metapicture is "the place where pictures reveal and "know" themselves". Metapicture is a picture theory, but not a theory of picture. In picture theory, the picture is not a passive object of explanation. We not only look for a theory of pictures but also pictures of theory. (Mitchell, 1994: 82).

Mitchell in "Picture Theory" classify four dimensions of metapicture, i.e.: 1) picture as a representation of itself, 2) picture as a representation of general characteristic/class, 3) picture as a dialectical image that is capable of moving from one field of discourse to another, depends on where the picture was embedded, and 4) picture as a talking image that has infinite relation to the text.

Mitchell exemplifies Steinberg's drawing (the Spiral, 1964) as a representation of selfreference. A man in coat stands in the center of the spiral he has drawn. Steinberg's drawing is a kind of defying of barriers between inside and outside or first and second order. In this sense, metapicture is a picture about itself, the boundaries of the first and second-order of representation are dissolved in image. (Mitchell, 1995: 42).

The other example of meta-pictures is 'optical illusion' picture, such as the duck-rabbit drawing. (Mitchell, 1994: 48). This picture can be embedded in various disciplines and regimes of knowledge, from leisure, anthropology studies, psychology to philosophy. (Mitchell, 1994: 48). According to Mitchell, the metapicture is a piece of moveable cultural apparatus. They can 
move from an illustrative device to a central role picture, such as a summary image or hypericon. (Mitchell, 1994: 49).

\subsection{Biopicture}

In the biology approach, pictures are seen as living things. Pictures can transform and extinct (Mitchell, 2015: 34). Mitchell begins with returning to the question of the Galtonian photographs, why both old and new image is "strangely familiar". The reason is that we see the image as "a type or typical representation rather than as a representation of an individual". We can recognize smiley face stickers as a face, but not as any particular face. (Mitchell, 2015: 33) It is because we recognize that smiley face as species, not a specimen. (Mitchell, 2015: 34).

It is more difficult to destroy species (images) than a specimen (pictures). However, the endangered and extinction of species is possible in this era. An image in biology is considered as life animate species that can also extinct. (Mitchell, 2015: 34). If the human species is regarded by some people as endangered species when the "posthuman" notion has emerged, the images are beginning to be endangered when the digital operation has emerged. However, Mitchell thought that both 'posthuman' and 'the digital' image are not the end of human species and the images. He said that we can refuge the species in the field of fossil and clone. Both fossil and clone, are quite precisely image families. (Mitchell, 2015: 36). The possibility of human cloning has re-awakened traditional taboos on image-making, especially about the creation of artificial life. The idea of duplicating life-forms and of creating living organisms according to our own image has been predicted by myth and legend, science fiction or the biblical story. For example, Adam as the image and likeness of God. (Mitchell, 2015:20). In another essay, Mitchell explains the possibility of Biocybernetic reproduction of images that combines computer technology and biological science to makes an image cloning, for example, the image-making of dinosaurs in Jurassic Park Film. (Mitchell, 2003: 482).

\section{Conclusion}

The significant contribution of Mitchell's theory on the philosophy of image is a notion of picture as a living thing or subject. This contribution appears on his concept that ranges from the pictorial turn, the distinction of image and picture, mixed media, meta-picture, to biopicture. Picture is not seen merely as an object. The idea of "picture as subject" opens the way to the picture theory that speaks by themself, not to be hindered by many interpretations about them.

\section{References}

Derrida, Jacques, Writing, and Difference, translated by Alan Bass, London and New York, Routledge, 2002.

Glock, Hans-Johann, What is Analytic Philosophy, Cambridge: Cambridge University Press, 2008.

Mitchell, W.J.T., "The Metapictures” in Picture Theory, Chicago and London: The University of Chicago Press, 1994.

Mitchell, W.J.T., “The Pictorial Turn”, 1992, ArtForum 30:7 in Picture Theory, Chicago and London: University of Chicago Press, 1994.

Mitchell, W.J.T., "The Work of Art in The Age of Biocybernetic Reproduction” Modernism/modernity, Volume 10, Number 3, September 2003, pp. 481-500.

Mitchell, W.J.T., “There are no Visual Media”, 2005, SAGE Publications (London, Thousand Oaks, CA and New Delhi), Vol 4(2).

Mitchell, W.J.T., Image Science, Chicago and London: The University of Chicago Press, 2015. 
Wittgenstein, Ludwig, Tractatus Logico-Philosophicus, Translated by D. F. Pears and B. F. McGuinness, London and New York: Routledge, 2002

Verstegen, Ian, "The Birth of The Discipline, W.J.T. Mitchell and the Chicago School of Visual Studies", in W.J.T. Mitchell's Image Theory, KrešimirPurgar (ed.), New York: Routledge, 2017. 